\title{
A LAS PUERTAS DE HÁBITAT III
}

\author{
Julián Salas (Dr. Ingeniero Industrial - Profesor Ad Honorem DUyOT)
}

Nos invita el Dr. Fariña a reflexionar desde nuestras ópticas académicas sobre los veinte años transcurridos desde la creación de Ci[ur], afirmando que: '...desde entonces, han ocurrido cambios muy importantes y acelerados en la forma en la que los ciudadanos vivien sus ciudades como en los rerquisitos que estas deben de cumplir'. Esta es la intención de este trabajo que pretende cubrir cuatro décadas: desde la participación del autor en Hábitat I (Vacouver, 1976), hasta la que pretende que sea su meta profesional: participar en Hábitat III (Quito, 2016).

Lo que hoy conocemos como 'Programa de las Naciones Unidas para los Asentamientos Humanos', comenzó al início se los 1970 como 'Fundación Hábitat', órgano vinculado entonces al Programa de las Naciones Unidas para el Medio Ambiente (PNUMA). En 1976 se llevó a cabo, en Vancouver, Canadá, la Conferencia de las Naciones Unidas sobre Asentamientos Humanos (Hábitat I). En dicho evento, la Fundación Hábitat cambió de nombre y se transformó en 'Centro de las Naciones Unidas para los Asentamientos Humanos' (CNUAH), con sede en Nairobi, Kenia.

Veinte años después, se realizó la segunda Conferencia de las Naciones Unidas para los Asentamientos Humanos (Hábitat II), en Estambul, Turquía y hoy nos convocan a Hábitat III en octubre de 2016 en Quito, Ecuador.

La Declaración de Vancouver comenzaba con un Preámbulo en el que se denunciaba: "...la inaceptable situación de los asentamientos humanos, en circunstancias que son previsibles que puedan agravarse con el crecimiento de la inequidad económica y la actual urbanización descontrolada, a menos que se tomen medidas positivas y concretas a nivel nacional e internacional". La primera acción que debería ponerse en práctica, en opinión de Hábitat I, debería ser: "adoptar políticas de asentamientos humanos audaces, significativas $y$ eficaces $y$ estrategias de ordenación del territorio (...) que tengan en cuenta los asentamientos humanos como instrumento y objeto del desarrollo". Entre los principios generales, la mencionada Conferencia abogó en 1976 por mejorar la calidad de vida a través de una distribución más equitativa de los beneficios del desarrollo, la planificación y regulación del uso del suelo, la protección del medio ambiente, la integración de las mujeres y los jóvenes, y la rehabilitación de las personas desplazadas por catástrofes naturales y de origen humano.

La Declaración de 1976 establecía, que vivienda y servicios adecuados son un derecho humano básico y que los gobiernos deben ayudar a las autoridades locales para que participen en mayor medida en el desarrollo nacional. La Declaración hacía especial hincapié en que "el uso y tenencia de la tierra deben estar sujetos a control público". Veinte años después, 1996, con la participación de la práctica totalidad de jefes de estados y de gobiernos del mundo, con más de diez mil participantes y la abrumadora y activa presencia del 'tercer sector's1 se convocó la segunda Conferencia

81 Ver J. Salas, 'HÁBITAT: El implacable desarrollo del subdesarrollo', Rev. Urban no 3, ETSAM 1999, páginas 53 a 66 
de las Naciones Unidas sobre los Asentamientos Humanos (Hábitat II), en Estambul, Turquía:

'Nosotros, los Jefes de Estado y de Gobierno... aprovechamos la oportunidad de hacer nuestros los objetivos universales de garantizar una vivienda adecuada para todos y de lograr que los asentamientos humanos sean más seguros, salubres, habitables, equitativos, sostenibles y productivos'.

Hoy, al revisar la ingente documentación distribuída 'in situ' en dicha Conferencia, teniendo muy presentes algunas de las nuevas políticas puestas en práctica y analizando realizaciones inspiradas en los principios básicos que allí, en Estambul se discutieron, incluso apasionadamente, nos permitimos recordar algunos de los aportes conceptuales, que puede que para algunos suenen a superados, lo que no nos lo parece. Apuntemos algunos:

- El desarrollo rural y el desarrollo urbano son interdependientes. Debemos ampliar adecuadamente las infraestructuras, los servicios públicos y las oportunidades de empleo en las zonas rurales, a fin de hacerlas más atractivas.

- Se enfatizó el notabilísimo papel encomendado a los municipios y a las autoridades municipales como dinamizadores de la lucha contra el déficit ${ }^{82}$ de viviendas.

- Se reafirmó la voluntad para lograr progresivamente el derecho pleno en favor de la mejora de los asentamientos humanos degradados y la lucha contra la tugurización. En este aspecto, hemos de rememorar el protagonismo de las autoridades municipales participantes, y de forma muy especial, la del entonces Alcalde de Barcelona, Pasqual Maragall en su Discurso de la Apertura de la Conferencia.

- Federico Mayor, en su calidad de Secretario General de UNESCO, defendió en un discurso magistral el derecho universal a una vivienda digna, asequible y adecuada, convocando la activa participación de los sectores públicos y privados y a las organizaciones no gubernamentales, a todos los niveles.

- Defendimos, en nombre del Programa Latinoamericano CYTED ${ }^{83}$, el derecho a un techo, como una condición para el ejercicio de la ciudadanía, ya que, sin un cobijo digno, la familia está más cerca de la condición de sobrevivientes que de la de ciudadanos. La inmensa mayoría de los habitantes del Tercer Mundo nacen y mueren en una vivienda 'no terminada', en algo que no es una vivienda a la usanza del Norte, sino el soporte de un proceso de mutación y mejora continua.

- En Hábitat II, los gobiernos locales fueron reconocidos como uno de los principales socios de ONU Hábitat para la ejecución de las Agendas Hábitat I y Hábitat II: El Programa facilitará el fortalecimiento de las capacidades y

82 'Hambre de Vivienda' fue la expresión que acuñada por el autor, se abría camino entre los 'viviendistas' latinoamericanos. J. Salas: Contra el hambre de vivienda: Soluciones tecnológicas iberoamericanas. Edt. Escala, Bogota. Colombia. 1992.

83 J. Salas, '1987 Año Internacional de las Vivienda para las Personas sin Hogar', EL PAÍS, 12.11.1984. y J. Salas, 'De aquí a 20 años', EL PAÍS, 8.06.1996. 
promoverá la transferencia de tecnologías y conocimientos especializados apropiados.

Estambul finalizó con la siguiente reafirmación de esperanza en el futuro del sector: 'Con esta Conferencia se inicia una nueva era de cooperación, la era de una filosofía de solidaridad. Al acercarnos al siglo XXI, ofrecemos una visión positiva del desarrollo de asentamientos humanos sostenibles, la esperanza de un futuro común y una exhortación a participar en una empresa de indudable valor e interés, la de construir mancomunadamente un mundo en el que todos vivan en un hogar seguro con la promesa de una vida decorosa en condiciones de dignidad, buena salud, seguridad, felicidad y esperanza".

\section{CUARENTA AÑOS DESPUÉS DE HÁBITAT I}

Hábitat I y II se centraron en lo que debería hacerse, como puede comprobarse en las respectivas Declaraciones de Vancouver y de Estambul. Si Hábitat III sigue esta ruta, habrá mucho debate de por qué las ciudades están en el eje de la nueva agenda global, pero también habrá, muchos replanteamientos de cuestiones planteadas en documentos anteriores, ya que 'nuevos' temas como la gobernanza urbana, el papel de los entornos urbanos en el crecimiento económico, la cohesión social, y la adaptación al cambio climático y su mitigación, que hoy necesitan aún más atención.

Hábitat III también tiene que aclarar, por qué el compromiso de los gobiernos con los objetivos de las conferencias anteriores, no consiguieron las respuestas necesarias. Todavía, por ejemplo, hay muchos países en los que más de la mitad de su población urbana carecen de agua corriente.

Los gobiernos locales y regionales sugieren en las reuniones preparatorias de Hábitat III, que hay que centrarlo en quién debe actuar para aplicar las recomendaciones pertinentes de Hábitat I y II y de los próximos 'Objetivos para el Desarrollo Sostenible, 2015-2030'84 y qué apoyo necesitan para poder llevarlos a cabo. Los países que mejor están consiguiendo el cumplimiento de estos objetivos y recomendaciones, son los que cuentan con gobiernos locales más competentes, responsables y con mayores recursos.

84 El 13 de Enero de 2015, Jeffrey Sachs, Director de la SDSN de Naciones Unidas, y Miguel Ángel Moratinos, Presidente del Consejo Asesor de la Española REDS, presentaron en Madrid REDS: su misión, sus objetivos y su perspectiva de futuro: «enredar» a las generaciones futuras para construir un mundo más sostenible.

De los 17 objetivos del SDSN, nos permitimos mencionar, por las múltiples conexiones con la temática de este trabajo, los tres siguientes:

5. Alcanzar la igualdad entre los géneros y empoderar a todas las mujeres y niñas.

6. Garantizar la disponibilidad y la gestión sostenible del agua y el saneamiento para todos.

11. Conseguir que las ciudades y los asentamientos humanos sean inclusivos, seguros, resilientes y sostenibles.

De los 17 objetivos identificados hasta ahora en las negociaciones que están teniendo lugar en Naciones Unidas, la SDSN ha asignado a España la coordinación de tres ámbitos sumamente importantes: 'Energía', 'Género' y 'Agua'. 


\section{ASUNTOS CLAVES EN LA PREPARACIÓN DE HÁBITAT III}

Entre las actividades previas y preparatorias de Hábitat III, a la vista de los documentos editados, aparecen en nuestra opinión, cuatro áreas clave que inciden en la vivienda y en el logro de objetivos de desarrollo sostenible en las zonas urbanas:

a) La gestión de un mundo en constante proceso de urbanización, reforzando la gobernanza local y mejorando la colaboración entre los diferentes niveles de gobierno (nacional, regional, local).

b) Apoyo a los esfuerzos de las ciudades para innovar, construir soluciones creativas para desarrollar el potencial económico de las ciudades, con un efecto multiplicador en toda la nación de mejores condiciones de vida, especialmente para las ciudades con pocos ingresos.

c) Hacer frente a la urgente necesidad de abordar cuestiones de medio ambiente: cambio climático y riesgos de desastres.

d) Fortalecimiento de mecanismos que permitan una verdadera participación de la población en la toma de decisiones y garantizar la rendición de cuentas de los gobiernos a todos los niveles.

Al objeto de vislumbrar los posibles contenidos de Hábitat III, nada nos parece más pertinente que reproducir en la Tabla 1 las 'Áreas, Informes temáticos y Unidades de política' en los que trabaja el Equipo de Soporte Técnico Interinstitucional de las Naciones Unidas sobre los Objetivos de Desarrollo Sostenible.

\begin{tabular}{|c|c|c|}
\hline Áreas & Informes Temáticos & Unidades de Política \\
\hline $\begin{array}{l}\text { 1. Cohesión Social y Equidad } \\
\text { - Ciudades Habitables }\end{array}$ & $\begin{array}{l}\text { 1. Ciudades inclusivas (Género, } \\
\text { Juventud, Envejecimiento) } \\
\text { 2. Migración y refugiados en zonas } \\
\text { urbanas } \\
\text { 3. Ciudades Más Seguras } \\
\text { 4. Cultura Urbana y Patrimonio }\end{array}$ & $\begin{array}{l}\text { 1. Derecho a la Ciudad y Ciudades } \\
\text { para Todos } \\
\text { 2. Marco Urbano Sociocultural }\end{array}$ \\
\hline 2. Entorno Urbano & $\begin{array}{l}\text { 5. Normas Urbanas y Legislación } \\
\text { 6. Gobernanza Urbana } \\
\text { 7. Hacienda Municipal }\end{array}$ & $\begin{array}{l}\text { 3. Políticas Nacionales Urbanas } \\
\text { 4. Gobernanza r Urbana, } \\
\text { Capacidad y } \\
\text { Institucional } \\
\text { 5. Sistema Fiscal Local y Finanzas } \\
\text { Municipales } \\
\end{array}$ \\
\hline 3.Desarrollo del Espacio & $\begin{array}{l}\text { 8. Urbanismo, Ordenación del } \\
\text { Territorio y Diseño } \\
\text { 9.- Áreas, Informes temáticos y } \\
\text { unidades de política Suelo Urbano } \\
\text { 10.- Vínculos urbano-rurales } \\
\text { 11.- Espacio Público }\end{array}$ & $\begin{array}{l}\text { 6- Estrategias urbano-espaciales: } \\
\text { tierras de mercado y segregación }\end{array}$ \\
\hline 4.- Economía Urbana & $\begin{array}{l}\text { 12. Desarrollo Económico Local } \\
\text { 13. Empleo y medios de vida } \\
\text { 14. Sector Informal }\end{array}$ & $\begin{array}{l}\text { 7. Estrategias Urbanas de } \\
\text { Desarrollo Económico }\end{array}$ \\
\hline
\end{tabular}




\begin{tabular}{|l|l|l|}
\hline $\begin{array}{l}\text { 5. Ecología Urbana y Medio } \\
\text { Ambiente }\end{array}$ & $\begin{array}{l}\text { 15. Resiliencia Urbana } \\
\text { 16. Ecosistemas Urbanos y Gestión } \\
\text { de Recursos } \\
\text { 17. Ciudades, Cambio Climático y } \\
\text { Gestión del Riesgos de Desastres }\end{array}$ & 8. Ecología Urbana. Resiliencia \\
\hline $\begin{array}{l}\text { 6. Infraestructura Urbana y } \\
\text { Servicios Básicos }\end{array}$ & $\begin{array}{l}\text { servicios básicos, incluida la } \\
\text { energía } \\
\text { 19. Transporte y Movilidad } \\
\text { 20. Vivienda } \\
\text { 21. Ciudades Inteligentes } \\
\text { 22. Asentamientos Informales }\end{array}$ & 9. Servicios Urbanos y Tecnología \\
\end{tabular}

Figura 14. Áreas, informes temáticos y unidades de política ${ }^{85}$

Fuente: autor

\section{El implacable desarrollo del subdesarrollo: probable contexto HÁBITAT III}

Se prepara Hábitat III en un contexto cosmopolita de necesidades abrumadoras en materia de hábitat. Sin ánimo catastrofista y tratando en la medida de lo posible de basarnos en valores cuantitativos fiables, recogeremos seguidamente algunos hechos de contexto que estimamos destacables. La desigualdad desarrollo-subdesarrollo en materia de asentamientos humanos, cuantificada a nivel planetario con motivo de Hábitat I, ocasionó una extrema perplejidad cosmopolita y propició que se evaluasen con mayor detalle y continuidad, especialmente en los Informes del PNUD, la evolución de los resultados en materia de Habitabilidad Básica ${ }^{86}$. Súbitamente, sin más fundamento que la constatación de que no se habían cumplido las previsiones catastrofistas para las grandes urbes emanadas hace cuarenta años de Hábitat I (Vancouver, 1976), se abrió camino una nueva forma de ver lo urbano, de valorar la ciudad, incluso las ciudades millonarias en ciudadanos. Durante las últimas décadas del pasado siglo la urbanización creciente y las migraciones internas merecieron diagnósticos sumamente perniciosos. Con posterioridad, los planificadores urbanos trataron $^{87}$ de comprender en vano las razones por las que decenas de millones de habitantes optaban decididamente por hacinarse en México D. F., Sao Paulo, Shangai, Calcuta, Buenos Aires, Bombay... Coincidimos con la insistente recomendación, en la preparación de Hábitat III por corregir el público meta de sus trabajos y conclusiones. Si bien es cierto que sus destinatarios oficiales siguen siendo los gobiernos nacionales, se reconoce que la principal causa de algunos de los fracasos de Hábitat II (1996) fue el no percatarse de la necesidad de establecer alianzas más sólidas con el poder local y con las ONGs, fortaleciendo la capacidad de actuación de las organizaciones comunales y grupos vecinales para dirigir estos problemas globalmente. Recomendación que emana con fuerza de las conclusiones de Hábitat II.

\footnotetext{
85 Toward Habitat III World cities at a Crossroads; $\neq$ Cities WeWant $\neq$ HABITAT III

${ }^{86} \mathrm{El}$ sintagma 'Habitabilidad Básica' lo acuñaron y definieron, Colavidas y Salas en 1993 como:'... es la que colma las necesidades esenciales de cobijo que tenemos todas las personas. Su satisfacción requiere, pues, que se cubran las urgencias residenciales del vivir: no sólo las que conciernen al mero cobijo individual, sino también a los espacios públicos, las infraestructuras y los servicios elementales que constituyen, en conjunto, un asentamiento propicio para la reproducción vital'.

87 United Nations Centre for Human Settlements (HABITAT): Informe Mundial sobre los Asentamientos Humanos. ISBN 92-1-331015-3.
} 


\begin{tabular}{|c|c|c|c|}
\hline & HABITAT I & HABITAT II & HABITAT III \\
\hline Año de celebración & 1976 & 1996 & 2016 \\
\hline Lugar de celebración & Vancouver (Canadá) & Estambul (Turquía) & Quito (Ecuador) \\
\hline Población Mundial & 4.068 millones & 5.674 millones & (2015) 7.376 millones \\
\hline $\begin{array}{l}\text { Población urbana } \\
\text { porcentual mundial }\end{array}$ & $37.9 \%$ & $45.1 \%$ & $54.5 \%$ \\
\hline $\begin{array}{l}\text { Población viviendo en } \\
\text { tugurios }\end{array}$ & (Sin datos fiables) & (año 2000): 776,7 millones & (año 2014): 1.125 millones \\
\hline $\begin{array}{l}\text { Inequidad: } 20 \% \text { de } \\
\text { población más rica / } \\
20 \% \text { de población más } \\
\text { pobre }\end{array}$ & $\begin{array}{l}\text { (1960) 30,5 veces más } \\
\text { ricos }\end{array}$ & $\begin{array}{l}\text { (1989) 59,1 veces más } \\
\text { ricos }\end{array}$ & $\begin{array}{l}\text { (2000) 78, } 2 \text { veces más ricos. } \\
\text { NOTA: El } 1 \% \text { ( } 7,2 \text { Millones) } \\
\text { de los habitantes más ricos } \\
\text { del mundo acaparan una } \\
\text { riqueza igual al } 99 \% \text { de } \\
\text { población restante. }\end{array}$ \\
\hline
\end{tabular}

Figura 15. Datos del 'contexto' previsible en el que se desarrollará Hábitat III

Fuente: el autor, en base a información del PNUD, OXFAM - Intermón; Programa CYTED ${ }^{88}$

La situación universal del hábitat hoy, 2015, en modo alguno podría calificarse de aceptable ni tampoco de esperanzadora, puede que ese pesimismo realista fuese la principal causa de la convocatoria de HÁBITAT I. Seguidamente analizaremos algunos hechos y datos, pero las perspectivas para HABITAT III no son halagüeñas, aunque en nuestra opinión se siguen ensalzando algunos datos 'menos malos' (fundamentalmente expresados en valores porcentuales) y silenciando otros realmente más que preocupantes (generalmente expresados en valores absolutos), puede que con la intención de inyectar ánimo positivo.

\section{Hechos de extraordinaria importancia acaecidos en el sector entre 2000- 2015:}

\section{- 2007}

La población urbana mundial sobrepasó a la población rural. La humanidad ha sido testigo de uno de los eventos más significativos de su historia: El Homo Sapiens se ha convertido en un Homo Urbanus. El que la ciudad haya vencido cuantitativamente al mundo rural es un hecho remarcable, si se tiene en cuenta que tan solo hace 200 años la existencia humana era fundamentalmente rural, con tan solo un $3 \%$ de la población del planeta residiendo en áreas urbanas ${ }^{89}$. El presente es urbano y el futuro lo será cada vez más. Incluso las sociedades menos avanzadas de África y Asia se urbanizan rápidamente y se espera que para el año 2030 no haya un solo continente cuya población sea predominantemente rural.

88 CEPAL: Alojar el Desarrollo: Una tarea para los asentamientos humanos. Documento LC / L906. CONF.85 / 3 . Ver Actas de la Reunión CYTED: Iberoamérica ante HABITAT Il. Ministerio de Vivienda de España.

89 Eduardo López Moreno Ciudad ONU-Hábitat. Desanimo o Esperanza en un Mundo de Realidades Contrastadas. CIUDAD SOSTENIBLE: LOS RETOS DE LA POBREZA URBANA. II Congreso Internacional de Desarrollo Humano. Madrid - 22 y 23 de abril de 2009 
Para el año 2050, seis de cada diez habitantes del orbe serán urbanos. Como puede verse en la Tabla 2, la población urbana crece de forma muy notable.

\section{- 2011}

El Programa del PNUD anunció oficialmente que el mundo acababa de superar los 7.000 millones de habitantes, información nada baladí si se tienen presentes algunos datos de contexto como: que hasta 1814 el mundo no alcanzó los 1.000 primeros millones de habitantes, y que cada día, alrededor de 193 mil personas se agregan a la población urbana del mundo, un poco más de dos por segundo, del orden de 72 millones de crecimiento 'neto' anual. Sin catastrofísmo, pero sí preocupado por lo que la reciente noticia bien documentada representa ${ }^{90}$, hemos de señalar que previsiones científicamente justificadas con un $95 \%$ de probabilidad anuncian que la población en el 2050 será de 9.000 millones de habitantes y que, contra todos los pronosticos fiables 'hasta el momento', la población mundial oscilará entre 9.000 y 13.200 millones de habitantes en el año 2100 .

\section{- 2015}

El 1\% de los habitantes más ricos del mundo (7, 2 millones) acaparan una cantidad de riqueza igual a la del $99 \%$ de la población restante $(7.128 \text { millones })^{91}$. En opinión de Joseph Stiglitz ${ }^{92}$ "La extrema desigualdad en términos de renta y riqueza que existe actualmente en gran parte del mundo es perjudicial para nuestra economía y nuestra sociedad, y socava nuestra política. Si bien esta situación debería preocuparnos a todos, lo cierto es que son las personas más pobres quienes más la sufren: no solo sus vidas se ven afectadas por una gran inequidad, sino que también carecen, en gran medida, de igualdad de oportunidades. El informe de Oxfam nos recuerda, en un momento muy oportuno, que cualquier iniciativa que realmente pretenda erradicar la pobreza debe hacer frente a las decisiones sobre políticas públicas que generan y perpetúan la desigualdad."

\section{- 2000-2015}

El numero de habitantes viviendo en tugurios era en el año 2000 muy superior a los 923 millones que contabilizó y difundió los 'Objetivos del Milenio', ya que sólo se refería a la población urbana. Hoy, pese al éxito cierto que anuncia NNUU asegurando que las previsiones de la Meta 11 de los Objetivos del Milenio se han superado en un $220 \%$, hoy, hay más de 2.000 millones de personas (urbanas y rurales) viven en tugurios ${ }^{93}$. ONU-Hábitat en su informe bienal para 2010: 'Estado de las Ciudades del Mundo 2010/2011: Reducir la Brecha Urbana', dice que los 22 millones de personas de países en desarrollo que han dejado de vivir en barrios de tugurios cada año entre 2000 y 2010 lo hicieron gracias al mejoramiento de estos barrios. Aunque sea una buena nueva, todavía es necesario un mayor esfuerzo para la reducción general de la brecha urbana mundial, ya que en realidad el "número absoluto" de habitantes urbanos en tugurios tugurios ha aumentado: de 776,7 millones en 2000 a unos 827,6 millones en 2010.' Parece necesario insistir,

\footnotetext{
90 Sarah C. P. Williams, Univ. Univ. Washington, UW Seattle, Rev. Science 19.09.2014

${ }^{91}$ Informe Mundial OXFAM-INTERMÓN sobre Inequida, 13.01.2015.

92 Joseph Stiglitz, professor de la Universidad de Columbia y premio nobel de Economía

93 J. Salas, ponencia: 'The Informal Habitat Sector: the most important absentee at World SB14', Barcelona 'SB14', 29.10.2014.
} 
que esta cita, cierta, se refiere únicamente a tugurios urbanos, y que nuestro trabajo detalla el total de personas tugurizadas en el mundo.

\section{- 2000-2015}

El deterioro global de la 'Habitabilidad Básica' en valores absolutos sigue creciendo paulatinamente en lo que ha transcurrido del siglo presente. El concepto de 'Habitabilidad Básica' hace su camino, y resulta más que nunca necesario denunciar que cada vez son más los que no tienen 'vivienda' ni tan siquiera 'Habitabilidad Básica'. Intentemos acercarnos a 'contar' cuantos son los habitantes que no tienen Habitabilidad Básica, en el supuesto que estimamos plausible que lo son gran parte de los que viven en tugurios (urbanos y rurales) y los alojados o acogidos en campamentos de refugiados.

- El suministro de agua. El número de habitantes que hoy cuentan con suministro de agua, ciertamente ha crecido extraordinariamente desde el 2000, pero los problemas debidos al agua han aumentado. Según Ban Ki-Moon, Secretario General de Naciones Unidas: 'Es inaceptable que cerca de la mitad de la población de los países en desarrollo tenga problemas de salud provocados por deficiencias en materia de agua o que los habitantes de los barrios marginales paguen cinco e incluso diez veces más por el agua que consumen que los residentes ricos de las grandes ciudades'. Es más que evidente, que el abastecimiento sostenible de agua potable, junto con un alcantarillado e higiene adecuados, conforman la línea de vanguardia en el combate contra las enfermedades y la muerte vinculadas al agua.

- Letrinas y saneamiento. Aunque es cierto que según datos de NNUU que entre 2000 y 2011, unos 1.900 millones de personas tuvieron acceso a nuevas letrinas, inodoros u otras instalaciones de saneamiento mejoradas, resulta inadmisible que más de 1.000 millones de personas residentes en comunidades rurales carezcan de retretes y tengan que defecar al aire libre.

- Cocinas y fogones. 'El 39\% de la población mundial utiliza la biomasa como fuente de energía para cocinar y calentarse ${ }^{\prime 94}$. Por otra parte, la exposición al humo de la cocina es el cuarto riesgo para la salud en el mundo, causando más de cuatro millones de muertes al año.

- Techos y suelos. El uso de mosquiteras y lonas, así como la no utilización en cubiertas de elementos con asbesto, son precauciones claramente recomendables para eliminar la malaria y la asbestosis. Los pavimentos a base de tierra compactada resultan altamente peligrosos.

Coincidimos con Jeffrey Sachs cuando afirma en su libro 'El Fin de la Pobreza' que: "Cada año sucumben a la malaria más de un millón de niños africanos, quizá hasta tres millones. Esa catástrofe espantosa sucede a pesar de que la enfermedad se puede prevenir en parte por medio del uso de mosquiteras, lonas plásticas impermeables $y$ otros controles ambientales...no existe ninguna excusa que justifique que esa enfermedad se cobre millones de vidas todos los años."

94 Global Alliance for Clean Cookstoves, 2013. 